\title{
Who is Interested in Knowing the Sagittal Balance in Elderly Spine Deformities? Is it the Patient, the Surgeon or the Industry?
}

\author{
Sergio Zylbersztejn* \\ Department of Orthopedics, Federal University of Health Sciences of Porto Alegre, Brazil
}

Received: January 30, 2018; Published: February 16, 2018

*Corresponding author: Sergio Zylbersztejn, Assistant Professor, Discipline of Orthopedics, Federal University of Health Sciences of Porto Alegre, Brazil, Email: sergiozyl@gmail.com

\section{Opinion}

I believe that an analysis of sagittal alignment and its practical incongruities is a relevant and current issue in spinal surgery. During one of our Service of Spine Surgery weekly meetings, we discussed a clinical case about axial low back pain without root symptoms. The 68-year-old female patient, suddenly had pain with neurogenic claudication interfering with her daily life activities. The radiograph image showed a scoliosis and a spondylolisthesis grade I L4L5, both with degenerative changes, while Magnetic Resonance Imaging showed vertebral canal stenosis with yellow ligament hypertrophy. However, the dynamic exams of the spine did not present gross instability of the motor unit at L4L5, indicating a sagittal alignment within normal range.

In our discussion, several practical questions arose:

1. Where is the pain coming from: the scoliosis or the spondylolisthesis at L4L5?

2. What is more important to treat: the scoliosis or the spondylolisthesis at L4L5

3. Which alignment should we pay more attention to: the coronal (scoliosis) or the sagittal (spondylolisthesis at L4L5)?

4. Is there a real need to correct her scoliosis considering her sagittal alignment is within normal range?

5. What is the most appropriate technique: to perform a long fusion to decompress and correct scoliosis by posterior approach; or to decompress the L4L5 level with spondylolisthesis and fuse in case of instability in the intraoperative by posterior approach?

Before revealing the group's conclusion, I'll raise some considerations focusing on: the patient, the surgeon and the industry.

\section{Patient}

According to the World Health Organization (WHO), by 2050 , the number of people over 60 years of age will reach 2 billion, more than double the 900 million individuals in this age group as of 2015. The elderly will represent one-fifth of the planet's population. Thus, there will be an exponential increase in patients with scoliosis and degenerative changes who could undergo surgical treatments [1].

\section{Spine Surgeon}

As a result, scientists began to place greater importance on the measurements of the spine as indicators of the best procedure to help the patient. Questions such as what would be the ideal alignment for the spine and its impact on patients' quality of life are becoming increasingly frequent in discussions regarding the scoliosis treatment. In the mid-twentieth century, Cobb's angle measurement provided full guidance for surgical treatment of spinal deformity. However, at the end of the twentieth century, Dubos set introduced the concept that isolated balance and alignment analysis were not enough to analyze the spine. In his view, the inclusion of the pelvis and lower limbs could bring important information when analyzing the spine [2].

The focus of Dubos set's work showed that failure to integrate the pelvis with the spine would bring adverse clinical outcomes to the patient, resulting in iatrogenic diseases such as flat-buttock and kyphotic decompensation syndrome. These negative outcomes are known as fixed sagittal imbalance. The set of lines that provide the so-called "precious" information to restore sagittal alignment, are: Pelvic Incidence (PI), Sacral Slope (SS), Lumbar Lordoses (LL), Thoracic Kyphosis, Sacral femoral distance and the C7 Plumb line [3]. Due to these multiple spine measurements, it becomes increasingly complex for the spine surgeon to calculate the sagittal alignment, prompting the industry to develop new technologies to facilitate this process. 


\section{Industry}

Since then, several software programs have been developed to help surgeons calculate the sagittal balance, performing these measurements with Cartesian results. Having said that, another question arises: is the multiple line analysis fully representative of the clinical state of the patient? As of now, this answer remains open. Lately it has been observed that even when all measurements indicate surgery, there is still a high percentage that after the surgery the patient will face consequences such as pseudoarthrosis, hypolordotic fusions and long fusions, which can remove the patient's ability to provide pelvic compensation [4].

When considering elderly patients, it is important to emphasize that they are usually carriers of morbidities that might also interfere with the outcomes of the surgical treatment for sagittal imbalance. These morbidities may be associated with the deficit of proprioception, muscular atrophy, visual and additive deficit which may interfere in a negative way in the best surgical proposal to recover their sagittal alignment [5]. More recently, Vrtovec et al. [6] carried out a review stating that the PI (pelvic incidence) is the most significant measurement in the spine sagittal alignment, as related to spine deformities in adults. Then, it just confirms the Dubos set's finding.

However, we do not know if the imbalance which to do clinical symptoms to the patient. The authors Pierre Roussouly and Colin Nnadi and Cavanilles-Walker JM made an important and simple contribution to spine surgeons searching to know the quality of the outcome: the focus should be on the measurement of IP in addition to the C7 Plumb line $[7,8]$. If both are normal, it means that it is the expected optimal surgical result. Going back to the initial clinical case, we concluded that the pain was originating from the L4L5 spondylolisthesis, and not from the scoliosis.
Therefore, the chosen procedure was the surgical intervention at that levels only, with the aim of decompressing and arthrodesing this motor unit. Lastly, the answer to the question posed at the beginning of this article relates to all of those who are interested in deciding the best treatment for the patient. These observations and the example of the clinical case give us an updated picture of the importance of considering not only the sagittal alignment but also other factors that might impact our choices when looking for best results for the patient.

\section{References}

1. Vincent GK, Velkoff VA (2010) The next four decades: the older population in the United States: 2010 to 2050. Current Population Reports. Population Estimates and Projections Series P25-1138.

2. Dubousset J (1998) Importance de la vertèbre pelvienne dans l'équilibre rachidien. Application à la chirurgie de la colonne vertébrale chez l'enfant et l'adolescent. In: Villeneuve P (Ed.), Pied équilibre et rachis, Frison-Roche, Paris, pp: 141-149.

3. Mendoza Lattes S, Ries Z, Gao Y, Weinstein SL (2010) Natural history of spinopelvic alignment differs from symptomatic deformity of the spine. Spine 35(16): E792-E798.

4. Yagis M, Ohne H, Kaneko S, Machida M, Yato Y, et al. (2018) Does corrective spine surgery improve the standing balance in patients with adult spinal deformity? Spine J 18(1): 36-43.

5. Vrtovec T, Janssen MM, Likar B, Castelein RM, Viergever MA, et al. (2012) A review of methods for evaluating the quantitative parameters of sagittal pelvic alignment. Spine J 12(5): 433-446.

6. Cheng I (2012) Commentary: spinopelvic parameters: how far have we come? Spine J 12(5): 447-448.

7. Roussouly P, Nnadi C (2010) Sagittal plane deformity: an overview of interpretation and management. Eur Spine J 19(11): 1824-1836.

8. Cavanilles-Walker JM, Ballestero C, Iborra M, Ubierna MT, Tomasi SO (2014) Adult spinal deformity: sagittal imbalance. International Journal of Orthopaedics 1(3): 64-72.

\begin{tabular}{|l|}
\hline \multicolumn{1}{|c|}{ Your next submission with Juniper Publishers } \\
will reach you the below assets \\
- Quality Editorial service \\
- Swift Peer Review \\
- Reprints availability \\
- E-prints Service \\
- Manuscript Podcast for convenient understanding \\
- Global attainment for your research \\
- Manuscript accessibility in different formats \\
( Pdf, E-pub, Full Text, Audio) \\
- Unceasing customer service \\
Track the below URL for one-step submission \\
https://juniperpublishers.com/online-submission.php \\
\hline
\end{tabular}

